\begin{tabular}{|c|cc|c|c|}
\hline & PORT SAID ENGINEERING RESEARCH JOURNAL & Faculty of Engineering - Port Said University \\
& Folume. (20) & No.1 & March 2016 & pp. 90:100
\end{tabular}

\title{
Numerical Model to Study Stability of Protection Layer at Downstream of Major Hydraulic Structures
}

\author{
Case study (New Assiut Barrage)
}

\author{
Ebtehal Sayed Mohamed, Osama K.S, Ahmed Mohamed Hassan Mirdan, Abdel-Azim M.Ali
}

\begin{abstract}
In terms of the importance of stilling basins in Egypt, the present paper was initiated with the impartial of investigating the stability of bed protection at downstream "D.S". An undistorted 3-D physical model was constructed for New Assiut Barrage (NAB) with a scale of 1:45. A riprap with a mean particle diameter of $16 \mathrm{~mm}$ was placed at the D.S. of the spillway of NAB; thirty (30) experiments were carried out. Thirteen (13) different discharges were investigated. The effect of the number of gates was studied. Measurements were undertaken, analyzed and compared with the results of different formulae. The obtained results indicated that the riprap was unstable in case of discharges more than $40.5 \mathrm{~L} / \mathrm{s} / \mathrm{gate}$. A numerical model (Flow-3D) was used and validated to simulate the velocity distributions at downstream. During this process, creating graphs inter-relating the tested variables and analyzing the undertaken simulations. The results were discussed in order to compare the physical model with the numerical model. It could be stated that the discrepancies of numerical results were in a range of less than $+/-25 \%$.
\end{abstract}

KEYWORDS: Riprap - Numerical model - Incipient motion -Stilling basin - Physical model- New Assiut Barrage.

\section{INTRODUCTION}

Stilling basins are used when designing heading-up hydraulic structures such as barrages, dam, weirs.....etc. They are energy dissipaters that are provided at D.S. Riprap is simultaneously added at the D.S. of stilling basin that is widely used to stabilize and protect the river bed. It is defined as a layer of protective mound of stones that are randomly placed. The (Flow-3D) program is selected to simulate the NAB, where the velocity distributions downstream stilling basin are obtained

The two main objectives of the present paper are to:

1. Calibrate the computational model, providing a sensitive analysis for some of the main parameters/models in Flow-3D and compare them with the physical model.

2. Validate the computational model using physical model discharge and flow depths measurements.

This paper presents the investigation phases, under the following headlines:

1) Literature review

2) Calibration of the computational model

3) Case study

4) Physical model

5) Experimental runs

6) Measurements

7) Numerical Modelling

8) Results analysis and discussions

9) Conclusions and recommendations
The present paper is considered as extend to the paper published by Ebtehal et al.(2015), which contained the results of experimental and theoretical study on New Assiut Barrage model,

\section{LITERATURES REVIEW}

Primarily, literature was reviewed in the field of stilling basins from which it was clear that many researchers investigated barrages, stilling basins and riprap.

(1970) investigated the effect of riprap grading experimentally. Anderson stated that in order to fill the gaps between the larger particles the layer thickness should prevent the attack on the base material and should be appreciably less than riprap material.

Simons and Senturk (1977) suggested that with a well distributed size range, the interstices formed by the larger particles are filled with the smaller sizes preventing formation of open pockets which affect the stability of the riprap layer. The ratio of maximum size $\mathrm{D}_{100}$ to median size $\mathrm{D}_{50}$ should be approximately two.

Knieb(1977) mentioned that the protective layer will be increasingly stable as the layer thickness conforms the relationship between riprap stability and thickness of riprap layer. Thickness should satisfy.

$$
\mathrm{T}_{\min }=1.5 * \mathrm{D}_{100}
$$


Where, $\mathrm{T}_{\min }$ is the minimum riprap thickness.

Isbash (1936), Mavis (1948), USBR (1958), Graf(1971), Römisch (1995), and Osama (1995) reported that the stable stone mean diameter is calculated by using different formulae.

Isbash (1936) developed an equation for stone movement

$$
\mathrm{V}_{\mathrm{av}}=\mathrm{C}\left[2 g\left(\frac{y_{s}-\gamma_{W}}{\gamma_{w}}\right)\right]^{\frac{1}{2}}\left(D_{50}\right)^{1 / 2}
$$

Mavis et al. (1948) published an equation for the competent bottom velocity. Data from about 400 tests were analyzed. The resulting equation is:

$$
\mathrm{V}_{\mathrm{b}}=4.3 \mathrm{D}_{50}{ }^{4 / 9}
$$

USBR (1958) developed a formula in order to investigate the maximum size of riprap mixture downstream of stilling basin. The different formulae related the stable mean stone diameter with the mean/bottom velocity, as follows:

$$
\mathrm{V}_{\mathrm{b}}=4.97 \sqrt{D_{100}} \text { (British unit) }
$$

The stone size $\mathrm{D}_{100}$ is equal to double $\mathrm{D}_{50}$.

$$
\mathrm{D}_{50}=\left(\mathrm{V}_{\mathrm{b}} / 3.88\right)^{2} \quad \text { (Metric unit) }
$$

Graf (1971) correlated the bed velocity with the bed particle diameter as:

$$
\mathrm{V}_{\mathrm{b}}=4 \sqrt{D_{50}}
$$

Römisch, K. et al. (1995) formulated the stability coefficient " $B$ "' to study the stability of riprap particles remembering that the stability of riprap downstream of a stilling basin depends on both velocity and turbulence level:

$$
\mathrm{B}^{\prime}=\frac{V_{b}(1+3 S D V)}{\sqrt{D_{50}, \Delta \Delta t}}
$$

Osama (1995) suggested that the value of modified Froude number gives the following relation between bed velocity $\mathrm{v}_{\mathrm{b}}$ and bed particle $\mathrm{D}_{50}$ :

$$
\mathrm{v}_{\mathrm{b}}=4.32 \sqrt{D_{50}}
$$

Seyed, et al. (2008) studied the incipient condition of riprap protection at the end of a stilling basin at downstream of a sluice gate. Flows with and without hydraulic jump were tested where eight different river gravel sizes were used as riprap grains (i.e. 8.75 to 47.5 $\mathrm{mm})$. The experiments were conducted with different gate openings. The results showed that at a constant discharge, the incipient flow depth decreases as the riprap size increased.

Miguel Rocha Silva (2012) and Dargahi et al. (2010) studied the applicability of a commercial "Computational Fluid Dynamics" model (Flow-3D) to simulate the flow into a geometry complex spillway was reviewed. To solve the governing equations of fluid flow, Flow-3D solves a modification of the commonly used Reynolds Average Navier-Stokes equations. Additionally, the software included algorithms to track the free surface and represent the geometrical details. As referred in Dargahi et al. (2010), the turbulence mixing length parameter has a huge importance in simulation stability and duration. The rule of thumb of 7\% referred in Flow-3D, 2010 appears to be a good estimate for this parameter value. However it is recommended that a sensitive analysis to this parameter should be done in each case study. The numerical results showed to be highly dependent of the cell size. In fact, smaller cells allow reproducing geometric details such as complex cross-sections and radial gates.

Seokkoo Kang and Fotis Sotiropoulos (2012) developed a numerical model capable of simulating threedimensional, turbulent free surface flows in natural waterways. Free surface motion is captured by coupling the two-phase level set method and the sharp-interface curvilinear immersed boundary (CURVIB) method. The model solves the three-dimensional, incompressible, unsteady Reynolds-averaged Navier-Stokes (RANS) and continuity equations in generalized curvilinear coordinates using a fractional step method extended to handle multiphase flows. Turbulence was modeled by a twoequation RANS model implemented in the context of the CURVIB method. The accuracy of the level set method is verified by applying it to simulate two- and threedimensional sloshing problems, and the potential of the model for simulating real life, turbulent free surface flows is demonstrated by applying it to carry out RANS simulation of flow past rock structures in a laboratory flume and flow in a field scale meandering channel. The simulations show that the method is able to accurately predict water surface elevation over complex hydraulic structures and bathymetry, and capture the transition between subcritical and supercritical flows without any special treatment.

Silvan Hug and Thomas Staubli (2012) illustrated an example of a flow simulation in the hydro power plant (HPP) Aratiatia, for heavily disturbed velocity distributions. In this power plant three turbines are fed from a common surge tank and are operated in parallel or individually. Details on the geometrical and numerical model are given, as well as the physical boundary conditions. The Optimal Weighted Integration for Circular Sections (OWICS) discharge integration method at GaussJacobi positions is used to calculate the flow rates in the circular measuring sections immediately upstream of the spiral casing for different operating conditions. The procedures employed for extraction of the relevant data from the simulated flow fields needed for integration of the flow rates are described. A comparison of the axial and cross velocity components on the individual paths resulting from the CFD simulations and the measurement shows good agreement. From this agreement it can be concluded that the shape of the disturbed velocity distributions as well the secondary flow is well predicted 
by the simulation. An analysis of the integrated path velocities show that the integration uncertainty remains below $1.3 \%$ for the chosen 8 path, two plane configuration, even for the worst operating condition.

\section{CALIBRATION OF THE COMPUTATIONL MODEL}

The calibration and validation of numerical models are extremely important and therefore it constitutes part of the analysis tasks in most of the CFD models. In fact, an ongoing effort to carry out validation against published or experimental data remains essential. This is really important to ensure modeling correctness and to provide a high confidence level in its application

\section{CASE STUDY}

$\mathrm{NAB}$ and the hydropower plant will comprise three main components. These are the hydropower plant with 4 units of bulb turbines, spillway equipped with 8 radial gates each $17 \mathrm{~m}$ wide and a double chamber navigation lock of $160 \mathrm{~m}$ long and $17 \mathrm{~m}$ wide. During construction, flow will be diverted through parts of the existing barrage structure in a two or, potentially, three-phase operation. NAB would provide an increase in the allowed head, allowing more water discharges into Ibrahimiya Canal and will improve navigation conditions. Moreover; it will include a low head hydropower plant providing about 40 Megawatts.

\section{PHYSICAL MODEL}

Due to scour problems D.S. barrages, a physical model was designed and constructed in the experimental hall of Hydraulic Research Institute (HRI) (i.e. the area of laboratory hall is $100 \mathrm{~m} \times 40 \mathrm{~m}$ from wall to the other wall). The model is undistorted model with scale 1:45. Moreover; calibration was executed. Thirty (30) tests were conducted for one type of riprap soil. The used size of riprap particle is $0.72 \mathrm{~m}$ (Prototype).

The physical model including the existing barrage and the new barrage is shown in figure 1 . The barrage model comprised a river reach of $4,000 \mathrm{~m} ; 1,000 \mathrm{~m}$ upstream and 3,000 m downstream. The model consisted of three parts; the entrance, the reach, and the exit. The model included all structural barrage components i.e. existing barrage sluiceway, new and existing navigation lock, new barrage, sluiceway, closure dam and Hydro Power Plant (HPP).

The model entrance was made of $0.25 \mathrm{~m}$ thick brick wall covered with $0.02 \mathrm{~m}$ cement mortar mixed with chemical isolated materials to prevent seepage from the model. The entrance has suitable dimension to evacuate the discharge from the pump. At the beginning of the model, there is a weir followed by bars of wood to distribute the incoming flow to the entire model width.

The modelled reach included all the prototype conditions. The bed of the model and the banks was made of cement mortar with thickness of $0.10 \mathrm{~m}$. The cross section in the study area was scaled and inserted in the model and levelled. The area between the cross sections was filled with mortar layer. Each vent of the spillway is equipped with bras radial gate with a radius of $12 \mathrm{~m}$ is used to regulate the flow, as shown in figure 2. A hand driven gearbox controlled the radial gate opening. The gear system composed of a vertical and horizontal level gears. The vertical gear is engaged with a steel rod and a handle. The gate closes or opens by moving the handle and the gate opening was measured by using a vertical scale. A sill under the radial gate was used and the distance between sill under the radial gate and the apron was $4.6 \mathrm{~m}$ (prototype) followed by an inclination apron with slope $1: 1.74\left(30^{\circ}\right)$ (the middle apron) and the rear apron with a horizontal length of $6.5 \mathrm{~cm}$ (Model) from the downstream nose of the piers. The sill under the gate was raised to an elevation of (41.60) (fore apron) in the prototype. There is an end step with an elevation of (38.50) in the prototype. The overall design length of the stilling basin is $1.97 \mathrm{~m}$ (Model) $88.65 \mathrm{~m}$ (prototype). The hydraulic structure model made of wood. This wood was painted very well by a waterproof material (plastic) to prevent wood from changing its volume by absorbing water.

The model exit consisted of the tailgate with length of $9.50 \mathrm{~m}$ to fit with the last cross section in the model. The tailgate is used to adjust the water level in the model and is made of $5 \mathrm{~mm}$ rectangular steel plate and hinged from bottom to provide an adjustable inclination which is installed at the downstream end of the model to control the D.S.tailwater depth. The model is provided with a recirculating system. There are two centrifugal pumps with different capacities; of $500 \mathrm{~L} / \mathrm{s}$ for each of them. These two pumps are connected with two pipelines 10 inches for each. The maximum feeding capacity of the system is 1 $\mathrm{m} 3 / \mathrm{s}(1000 \mathrm{~L} / \mathrm{s})$.

The model bed U.S. and D.S. the barrage was covered by a movable bed. Upstream New Assuit Barrage is followed by a $7.16 \mathrm{~m}$ (Model) (representing $322 \mathrm{~m}$ in the prototype). This part was covered by riprap, figure 3 . The riprap layer is $8.9 \mathrm{~m}$ long in the model (representing $400 \mathrm{~m}$ in the prototype) and is placed just downstream the solid apron at the left and the right side of the spillway, figure 4. Where, R1, R2, R3, R4 and R5 represented different types of riprap layer sizes, as shown in table 1 .

The minimum riprap thickness ranged between twice to three times the mean stone diameter. The downstream is shaped to distribute the flow uniformly. The geometric mean diameter of the riprap layer $\mathrm{D}_{50}$ is equal to $16.0 \mathrm{~mm}$. The tests carried out in HRI laboratory. The same type of riprap was used in all the tests. 
Table 1: Characteristics of the Designed Riprap Protection

\begin{tabular}{|c|c|c|c|}
\hline $\begin{array}{c}\text { Material } \\
\text { characteristics }\end{array}$ & D15 (mm) & D50 $(\mathrm{mm})$ & D85 $(\mathrm{mm})$ \\
\hline R1 & 7.76 & 15.51 & 31 \\
\hline $\mathbf{R} 2$ & 6 & 12 & 24 \\
\hline R3 & 4.11 & 8.2 & 16.4 \\
\hline R4 & 2.8 & 5.6 & 11.2 \\
\hline R5 & 1.8 & 3.6 & 7.2 \\
\hline
\end{tabular}

\section{EXPERIMENTAL RUNS}

Different scenarios were experimentally tested. Thirteen different discharges were tested. The discharge was changed from 700 to $7000 \mathrm{~m}^{3} / \mathrm{s}$ in prototype and from 51.53 to $515.3 \mathrm{~L} / \mathrm{s}$ in model, as shown in table 2 .

Table 2: Test Program for Stability of the River Bed Protection.

\begin{tabular}{|c|c|c|c|c|}
\hline \multirow{3}{*}{ Test No. } & Discharge & \multirow{2}{*}{ D.S.W.L } & G.0 & \multirow{3}{*}{ gates operation } \\
\hline & prototype & & Model & \\
\hline & $\mathrm{m} 3 / \mathrm{sec}$ & $\mathrm{m}$ asl & $\mathrm{cm}$ & \\
\hline 1 & 900 & 45.42 & 5.80 & 3 gates opened right spillway \\
\hline 2 & 1200 & 46.57 & 5.3 & 4 gates opened lift spillway \\
\hline 3 & 2200 & 47.11 & 14 & 3 gates opened lift spillway \\
\hline 4 & 2900 & 47.89 & 11.50 & 3 gates opened right spillway \\
\hline 5 & 2900 & 47.89 & fully open & $\begin{array}{l}2 \text { gates opened right spillway } \\
3 \text { gates opened lift spillway }\end{array}$ \\
\hline 6 & 5000 & 49.55 & fully open & \begin{tabular}{|l}
2 gates opened right spillway \\
4 gates opened lift spillway \\
\end{tabular} \\
\hline 7 & 5500 & 49.55 & fully open & $\begin{array}{l}2 \text { gates opened right spillway } \\
4 \text { gates opened lift spillway }\end{array}$ \\
\hline 8 & 6000 & 50.26 & fully open & 8 gates opened(right/lift) spillway \\
\hline
\end{tabular}

\section{MEASUREMENTS}

The model was equipped by many measuring devices and measurements were undertaken. For example:

- An electromagnetic flow-meter was used to measure the discharge during the tests.

- Electromagnetic current-meter type EMS, manufactured by Delft Hydraulic, Holland, was used to measure the flow velocity profiles at two cross sections D.S. the stilling basin.

- Point gauges were used to adjust the water level at the U.S. and D.S. gates.

- Digital camera was used for recording the scour downstream the apron.

The velocity was measured at cross section No.1 (C.S.No.1), which was located at the concrete slab end of the stilling basin at a distance of $1.96 \mathrm{~m}$ in the model from the beginning of the nose of pier to the end of apron. Riprap layer extends along the bed of the model. The velocity values were measured at four points in the vertical direction along the water depth at relative distances from the surface of $0.2,0.6,0.8$ and 0.9 of total water depth to represent the vertical velocity profile. The velocity values are measured at 0.9 of the total water depth to represent velocity values near to bed.

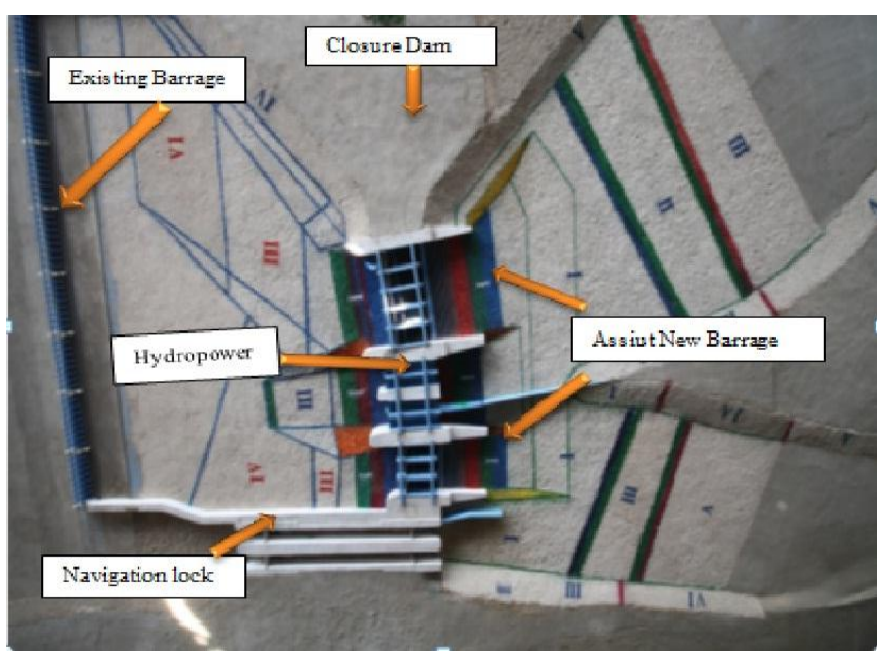

Figure 1: Layout of Assiut New Barrage
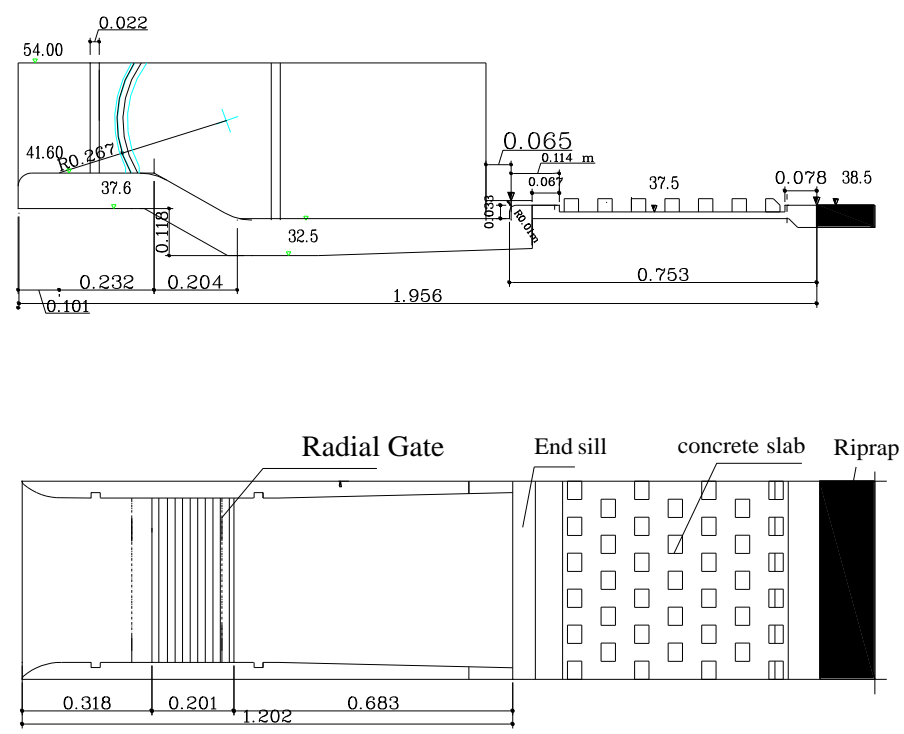

Figure 2: Longitudinal Section of Typical model Spillway

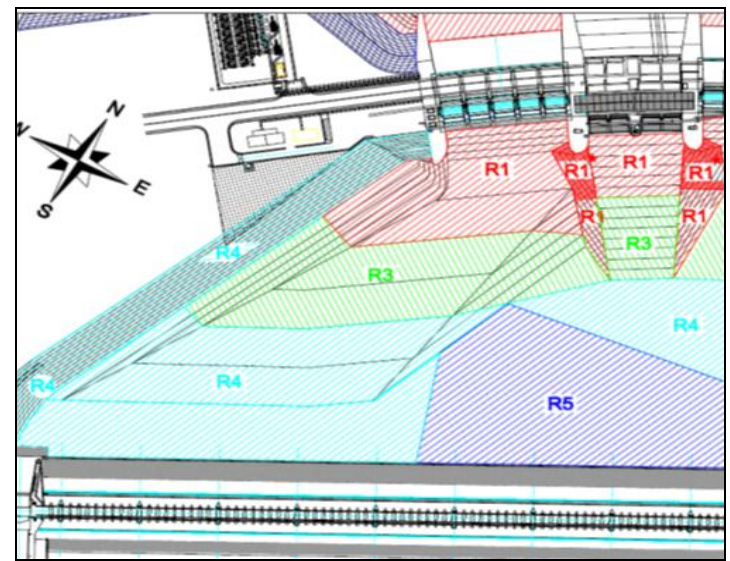


Figure 3: U.S. New Barrage

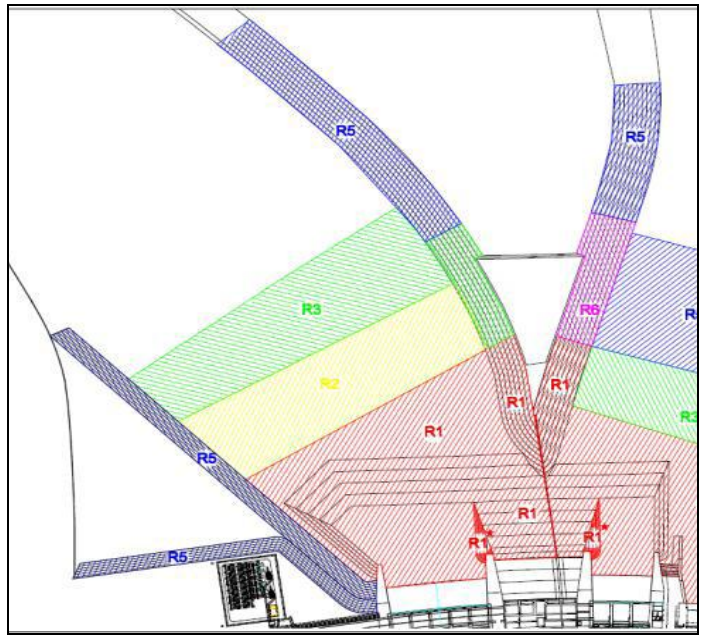

Figure 4: D.S. New Barrage

\section{NUMERICAL MODELING}

Numerical model was selected to predict the velocity distributions and the bottom velocity downstream the stilling basins for one open gate and compare these values with the measured values. Numerical models has the advantage of their economic cost, limited application time, the availability of varying all the considered parameters and receiving a good answer in no time. Flow-3D program was selected to be used during this study Flow-3D (2010).

The model was implemented by varying the parameter for each test series, assuming that all of the geometric variables are constant during the test series; except the gates operation, the discharge $(\mathrm{Q})$, the gate opening (GO) and consequently the tailwater level $\left(\mathrm{y}_{\mathrm{t}}\right)$.

Numerical replications were achieved to simulate the velocities distribution and bottom velocity downstream stilling basins. In order to get a good compromise between precision/accuracy and computation time, one independent mesh with cell size were used. Mesh cells are $1 \mathrm{~cm}$ in each direction for flow condition, as shown in figure 5.a and 5.b. The time window for analyzing the velocities distribution downstream stilling basins is carefully selected 2 seconds because it has been observed that the velocity seemed fixed after this time.

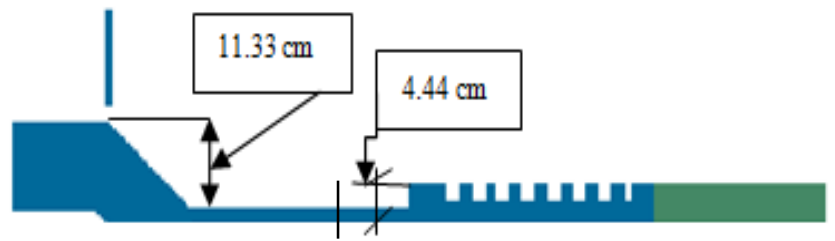

Figure 5.a: A screen shot of Numerical Model without mesh geometry

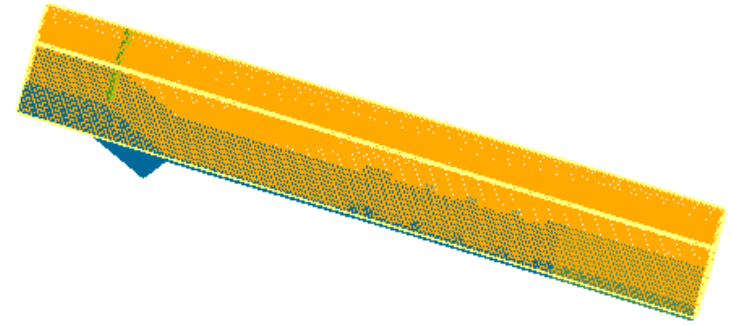

Figure 5.b: A screen shot of Numerical Model with mesh geometry

\section{RESULTS ANALYSIS AND DISCUSSIONS}

The stability of the protection layer downstream the barrage was studied by checking the used particle mean diameter $\mathrm{D}_{50}$ D.S. Assiut New barrage. The stone size stability of the protection layer D.S. New Assiut Barrage is checked against the mean/bottom velocity. The experimental results for the 30 experiments with constant mean particle diameter $\mathrm{D}_{50}=1.6 \mathrm{~cm}$ were compared to the results of six different formulae in order to calculate the stable mean stone diameter against the mean/bottom velocity.

\subsection{Sizing of protection Layer (Riprap)}

Figure 6 shows the relation between velocity and mean grain diameter of riprap for one of the tests, which the hydro power, the gate No.3 on left spillway and the gate No.7 on right spillway were closed. The passing discharge was $5500 \mathrm{~m}^{3} / \mathrm{s}$ (404.885 L/s Model). The gate opening was fully opened. The velocity values ranged from 0.087 to (0.743) $\mathrm{m}$ at cross section No.1. In this figure, equations $3,5,6,7$ and 8 were used to calculate the stone diameter as a function of the bottom velocity, while equation 2 was used to calculate the stone diameter as a function of the mean velocity used, as following:

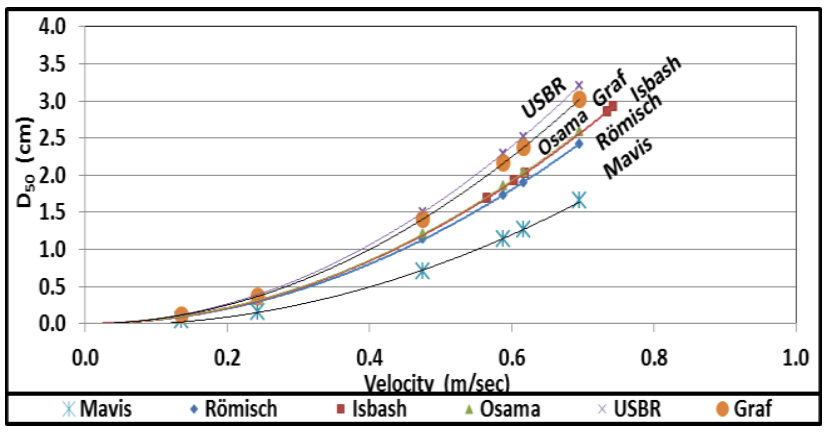

Figure 6: Relationship between $\mathrm{V}$ and $\mathrm{D}_{50}$

On applying equations, it could be concluded that the required stable riprap $D_{50}$ D.S. spillway ranged from 1.656 to $3.209 \mathrm{~cm}$ at cross section No.1. Theoretically it is clear that all equations were given that the maximum value of $\mathrm{D}_{50}$ was more than the used value of $\mathrm{D}_{50}$ which is $1.6 \mathrm{~cm}$., 
The maximum velocity and $\mathrm{D}_{50}$ were recorded D.S. of the opened gate, the value of the velocity and $\mathrm{D}_{50}$ are small of the D.S. of the closed gate No.3 and 7.

In these test, as shown in figure 7 and 8 it was noticed that there are more movements for the small riprap more than the previous test. There were some further movements for the large riprap. The scour hole was increased D.S. the opened gates. The upstream water level (just U.S New barrage) was found to be $51.71 \mathrm{~m}$ above sea level.

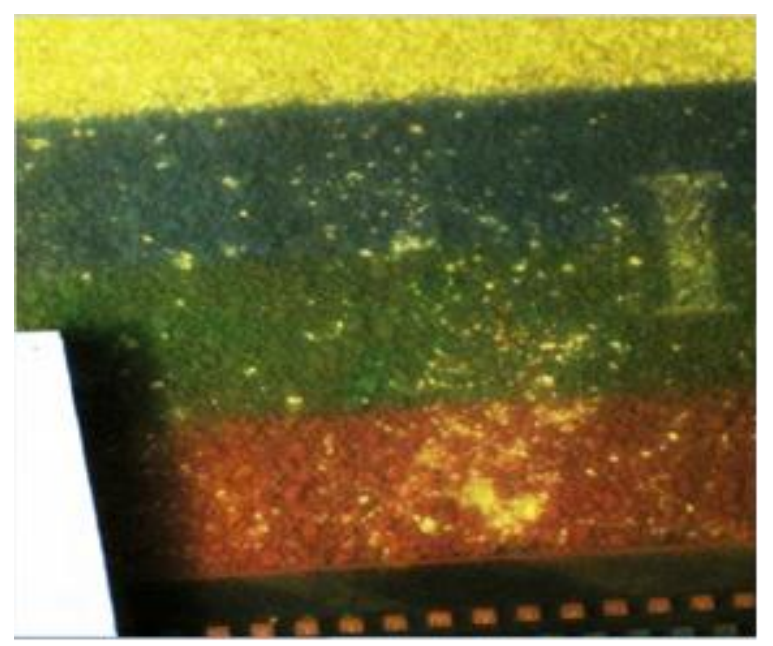

Figure 7: Riprap Conditions D.S. left Spillway

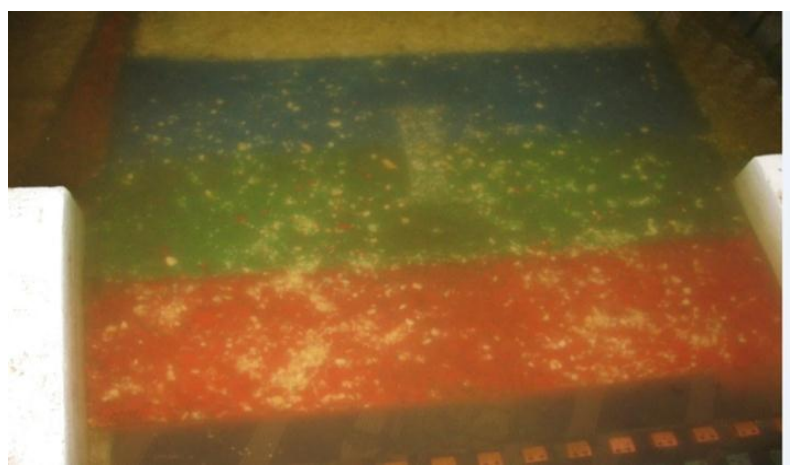

Figure 8: Riprap Conditions D.S. Right Spillway

According to the Theoretical Phase, Ebtehal et al. (2015) concluded the following:

Comparing the test results with the theoretical equations, it was found that Mavis equation gave the most economy and least stability of bed protection. Römisch, and Osama equations gave economy and stability of bed protection. Isbash, USBR and Graf equations gave more stability of bed protection and less economy. For more stability and economy, the designer can use Römisch and Osama equations. For more safety the designer can use Isbash, USBR and Graf equation,

\subsection{Results of the Sensitivity of Change Manning Coefficient}

Five different values of Manning coefficient are used; the values were $0.019,0.02,0.022,0.025$ and 0.03 . Figure 9 and Table 3, showed the comparison between the results of the laboratory and the results of Flow-3D program. It was found that the value of Manning coefficient equal to 0.03 gave velocity close to the results from laboratory in the region near the bed and, consequently, this value had been used.

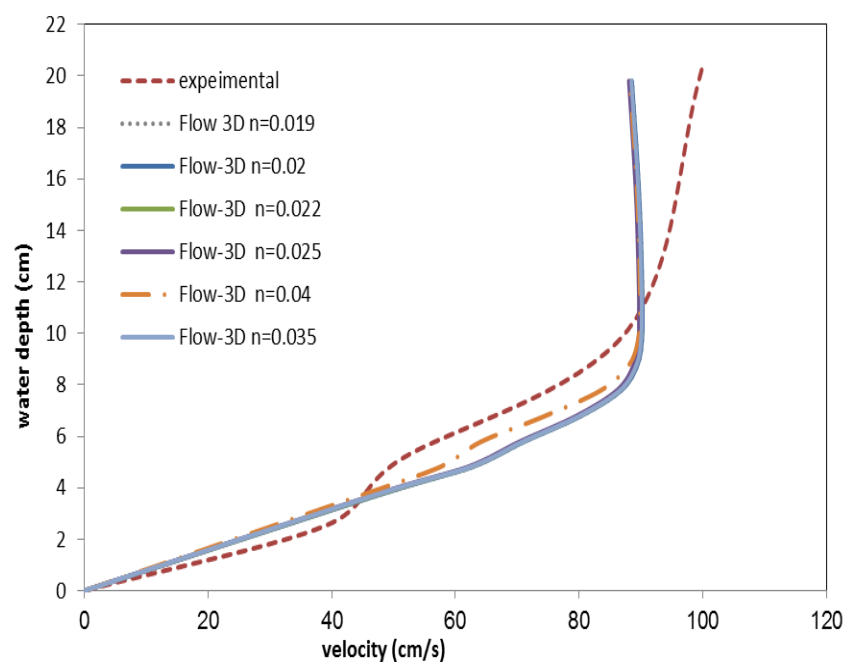

Figure 9: Comparison of experimental measurements with CFD (Flow-3D) for different values of Manning coefficient: $\mathrm{n}=0.019,0.02,0.022,0.025$ and 0.03

Table 3: Different values of Manning coefficient

\begin{tabular}{|c|c|c|c|c|c|}
\hline $\mathrm{n}$ & 0.019 & 0.020 & 0.022 & 0.025 & 0.030 \\
\hline $\mathrm{z}(\mathrm{cm})$ & $\mathrm{u}(\mathrm{cm} / \mathrm{s})$ & $\mathrm{u}(\mathrm{cm} / \mathrm{s})$ & $\mathrm{u}(\mathrm{cm} / \mathrm{s})$ & $\mathrm{u}(\mathrm{cm} / \mathrm{s})$ & $\mathrm{u}(\mathrm{cm} / \mathrm{s})$ \\
\hline 0.00 & 0.00 & 0.00 & 0.00 & 0.00 & 0.00 \\
\hline 3.80 & 48.63 & 48.57 & 48.34 & 47.89 & 43.75 \\
\hline 4.80 & 62.59 & 62.55 & 62.34 & 61.89 & 56.74 \\
\hline 5.80 & 71.18 & 71.14 & 70.92 & 70.47 & 64.51 \\
\hline 6.80 & 80.37 & 80.33 & 80.11 & 79.65 & 73.00 \\
\hline 7.80 & 86.88 & 86.85 & 86.64 & 86.19 & 79.35 \\
\hline 8.80 & 89.50 & 89.47 & 89.27 & 88.85 & 81.96 \\
\hline 9.80 & 90.21 & 90.19 & 89.99 & 89.58 & 82.67 \\
\hline 10.80 & 90.30 & 90.28 & 90.08 & 89.68 & 82.74 \\
\hline 11.80 & 90.24 & 90.21 & 90.02 & 89.63 & 82.65 \\
\hline 12.80 & 90.14 & 90.12 & 89.92 & 89.54 & 82.52 \\
\hline 13.80 & 90.02 & 90.00 & 89.80 & 89.42 & 82.38 \\
\hline 14.80 & 89.86 & 89.84 & 89.64 & 89.27 & 82.25 \\
\hline 15.80 & 89.65 & 89.63 & 89.44 & 89.07 & 82.13 \\
\hline 16.80 & 89.41 & 89.38 & 89.19 & 88.84 & 82.01 \\
\hline 17.80 & 89.14 & 89.11 & 88.92 & 88.58 & 81.90 \\
\hline 18.80 & 88.86 & 88.83 & 88.64 & 88.30 & 81.80 \\
\hline 19.80 & 88.57 & 88.54 & 88.36 & 88.03 & 81.70 \\
\hline
\end{tabular}

\subsection{Results of the Velocities Distribution}

Results of the Flow-3D simulations of the velocity distribution at downstream stilling basin were presented on graphs in figures 10 to 17 and were discussed. The 
analyzed results were plotted and presented in graphs to illustrate a comparison between the numerical results and the experimental results. Most of the figures showed that the points which measured from Flow-3D program and the results of laboratory are far from each other near the water surface but in the region near the bed, the results are almost close to each other as the follow:

The results of test No.1, when the hydropower was close, left spillway was close and right spillway was opened. The passing discharge was $900 \mathrm{~m}^{3} / \mathrm{s}(66.25 \mathrm{~L} / \mathrm{s}$ Model). The gate opening was constant for all opened gates and equal to $2.61 \mathrm{~m}(5.8 \mathrm{~cm}$ model $)$. The upstream water level just U.S. New barrage was $48.8 \mathrm{~m}$ above sea level (a.s.l) and the tailwater level was $45.42 \mathrm{~m}$ a.s.l. The velocity values ranged from 35.0 to $52.0 \mathrm{~cm} / \mathrm{sec}$, as in figure 10 .

Figure 10 presents a comparison between Flow-3D results and experimental results. It showed that the discrepancies of numerical results in the region near the bed were in a range of less than $+18.5 \%$

The results of test No.2 was executed under the condition of closing the hydro power, right spillway and gate No.3 at the left of spillway. The passing discharge (Q) was $1200 \mathrm{~m}^{3} / \mathrm{s}(88.338 \mathrm{~L} / \mathrm{s}$ Model). The gate opening was constant for all opened gates and was equal to $2.385 \mathrm{~m}$ (5.3 cm Model). The upstream water level just U.S. New Barrage was $50.8 \mathrm{~m}$ a.s.l and the tailwater level was 46.57 $\mathrm{m}$ a.s.l. The velocity ranged between 6.80 and $31.1 \mathrm{~cm} / \mathrm{s}$, As in Figure 11.

Figure 11 illustrates a comparison between Flow-3D results and experimental results. It showed the discrepancies of numerical results in the region near the bed were in a range of less than $-6 \%$.

In test No.3 only gates No.2, 4 and 5 were opened. The passing discharge was $2200 \mathrm{~m}^{3} / \mathrm{s}(161.953 \mathrm{~L} / \mathrm{s}$ Model). The gate opening was fully opened. The upstream water level just U.S. New Barrage was $51.8 \mathrm{~m}$ a.s.l and the tailwater level was $47.11 \mathrm{~m}$ a.s.l. The velocity ranged from 10.5 to $68.2 \mathrm{~cm} / \mathrm{s}$ at C.S.No.1, as in figure 12 .

Figure 12 illustrates a comparison between Flow-3D results and experimental results. It indicated the discrepancies of numerical results in the region near the bed are in a range of less than $25 \%$.

In test No.4 the hydro power and the left spillway were closed the right spillway was opened. The passing discharge was $2900 \mathrm{~m}^{3} / \mathrm{s}(213.485 \mathrm{~L} / \mathrm{s}$ Model). The gate opening was constant for all opened gates and equal to $5.18 \mathrm{~m}(11.5 \mathrm{~cm}$ Model). The upstream water level just U.S. New barrage was $52.0 \mathrm{~m}$ a.s.l and the tailwater level was $47.89 \mathrm{~m}$ a.s.l. The velocity ranged from 43.3 to $81.6 \mathrm{~cm} / \mathrm{sec}$ at C.S.No.1, as in figures 13 .
Figure 13 provides a comparison between Flow-3D results and experimental results. This figure declared that the discrepancies of numerical results in the region near the bed are in a range of less than $12.5 \%$

In test No.5 only gates No.2, 4 and 5 on left spillway and gates No.6 and 8 on right spillway were opened. The passing discharge was $2900 \mathrm{~m}^{3} / \mathrm{s}(213.485 \mathrm{~L} / \mathrm{s}$ model $)$, the gate opening was fully opened. The upstream water level just U.S. New barrage was $50.8 \mathrm{~m}$ a.s.l and the tailwater level was $47.89 \mathrm{~m}$ a.s.l. The velocity was ranged from 7.6 to $55.1 \mathrm{~cm} / \mathrm{sec}$ at C.S.No.1, as in figures 14 .

Figure 14 illustrates a comparison between Flow-3D results and experimental results. It showed that the discrepancies of numerical results in the region near the bed were in a range of less than $3 \%$.

The results of test No.6, where the hydropower, the gate No.3 on left spillway and the gate No. 7 on right spillway were closed. The passing discharge was 5000 $\mathrm{m}^{3} / \mathrm{s}$ (368.077 L/s model). The gate opening was fully opened. The upstream water level just U.S. New Barrage was $51.61 \mathrm{~m}$ a.s.l and the tailwater level was $49.55 \mathrm{~m}$ a.s.l. The velocity ranged from 16.9 to $74.1 \mathrm{~cm} / \mathrm{s}$ at C.S.No.1, as in figures 15 .

Figure 15 illustrates a comparison between Flow-3D results and experimental results. It was found that the discrepancies of numerical results were in a range of less than $20 \%$.

In test No.7 the hydropower, gate No.3 on left spillway and gate No.7 on right spillway were closed. The passing discharge was $5500 \mathrm{~m}^{3} / \mathrm{s}(404.885 \mathrm{~L} / \mathrm{s}$ Model). The gate opening was fully opened. The upstream water level just U.S. New barrage was $51.71 \mathrm{~m}$ a.s.l and the tailwater level was $49.55 \mathrm{~m}$ a.s.l. The velocity ranged from 8.7 to $74.3 \mathrm{~cm} / \mathrm{s}$ at C.S.No.1, as in figures 16 .

Figure 16 presents a comparison between (Flow-3D) results and experimental results. It showed that the discrepancies of numerical results in the region near the bed were in a range of less than $25 \%$.

The results of test No.8, where the hydropower was closed, left spillway and right spillway were opened. The passing discharge was $6000 \mathrm{~m}^{3} / \mathrm{s}$ (441.693 L/s Model), The gate opening was fully opened. The upstream water level just U.S. New barrage was $51.38 \mathrm{~m}$ a.s.l and the tailwater level was $50.26 \mathrm{~m}$ a.s.l. The velocity ranged from 32.7 to $53.4 \mathrm{~cm} / \mathrm{sec}$ at C.S.No.1, as in figure 17 .

Figure 17 illustrates a comparison between Flow-3D results and experimental results. It indicated that the discrepancies of numerical results in the region near the bed were in a range of less than $7 \%$. 


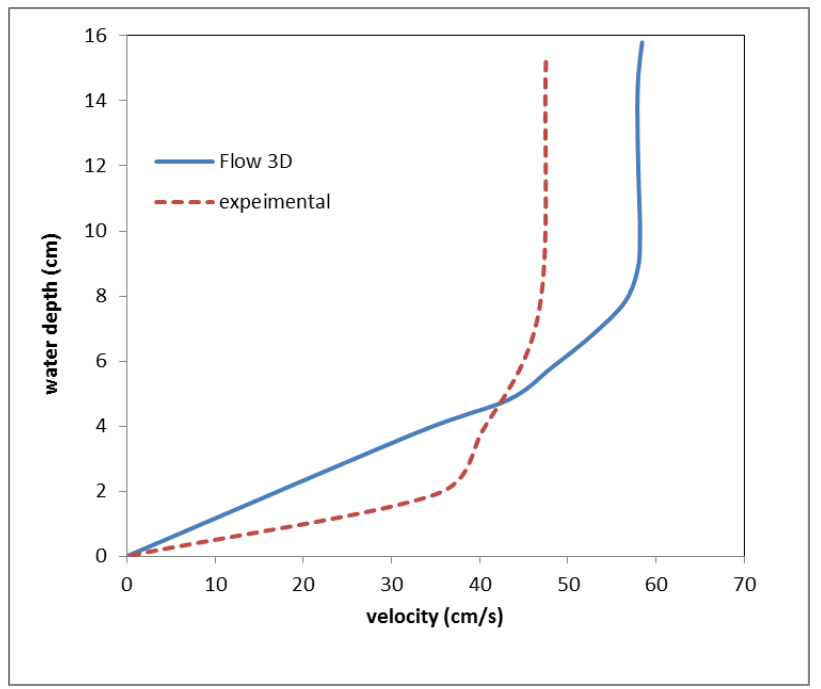

Figure 10: Comparison of velocities distribution by (Flow-3D) and experimental measurements results for test No.1.

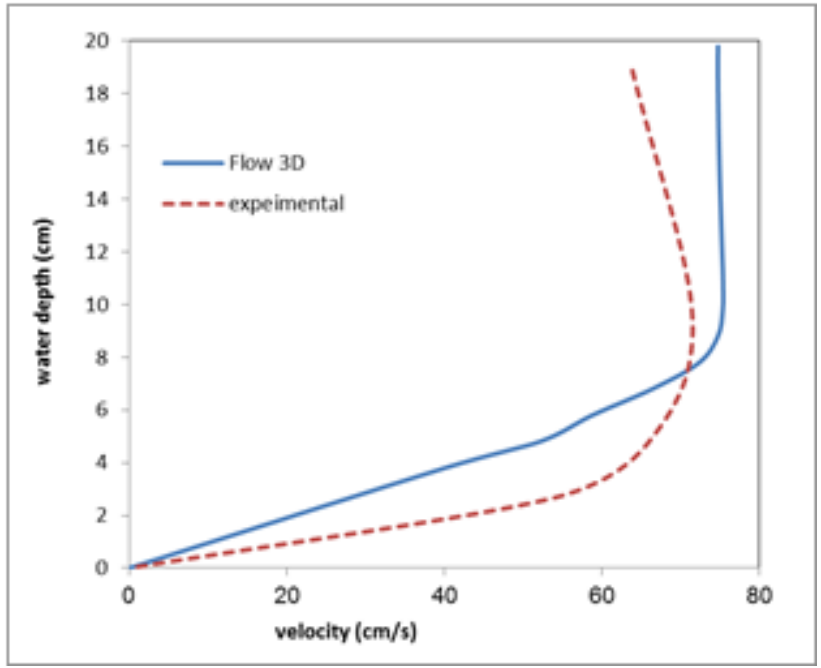

Figure 11: Comparison of velocities distribution by (Flow-3D) and experimental measurements results for test No.2.

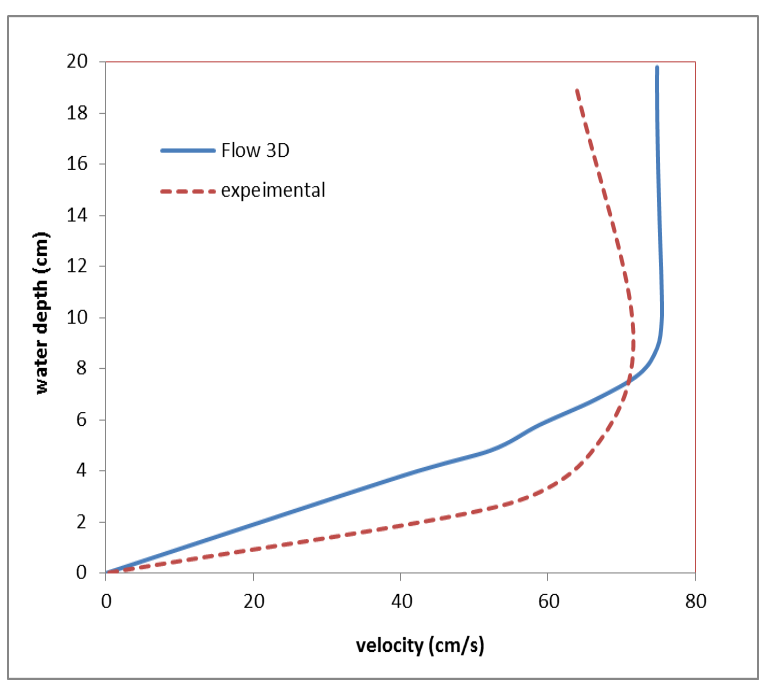

Figure 12: Comparison of velocities distribution by (Flow-3D) and experimental measurements results for test No.3.

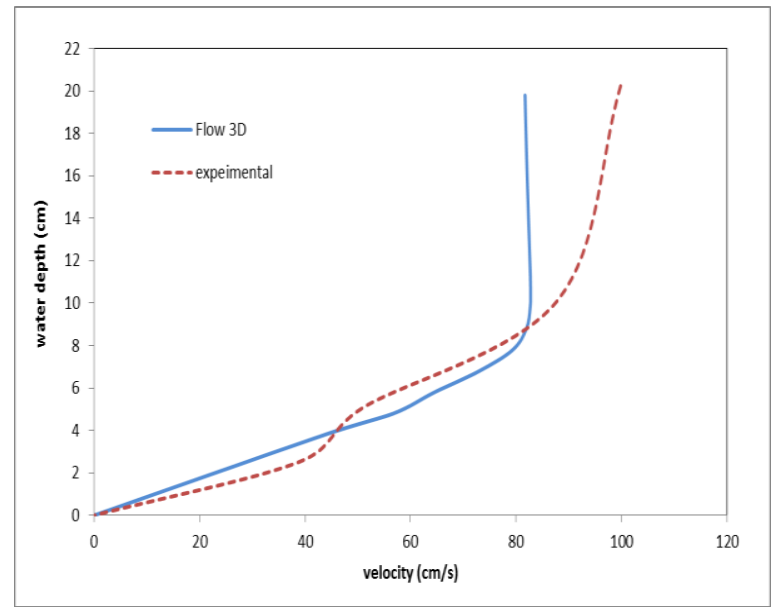

Figure 13: Comparison of velocities distribution by (Flow-3D) and experimental measurements results for test No.4.

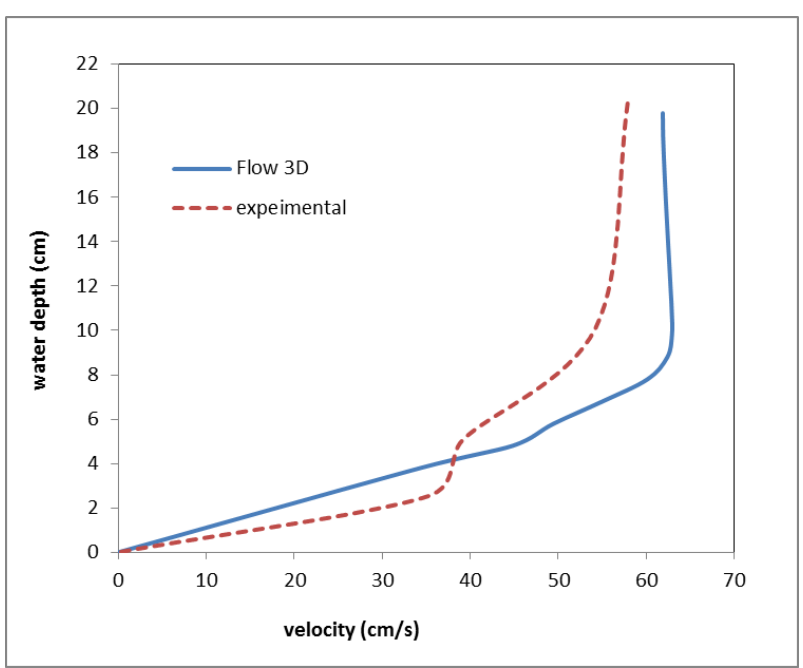

Figure 14: Comparison of velocities distribution by (Flow-3D) and experimental measurements results for test No.5.

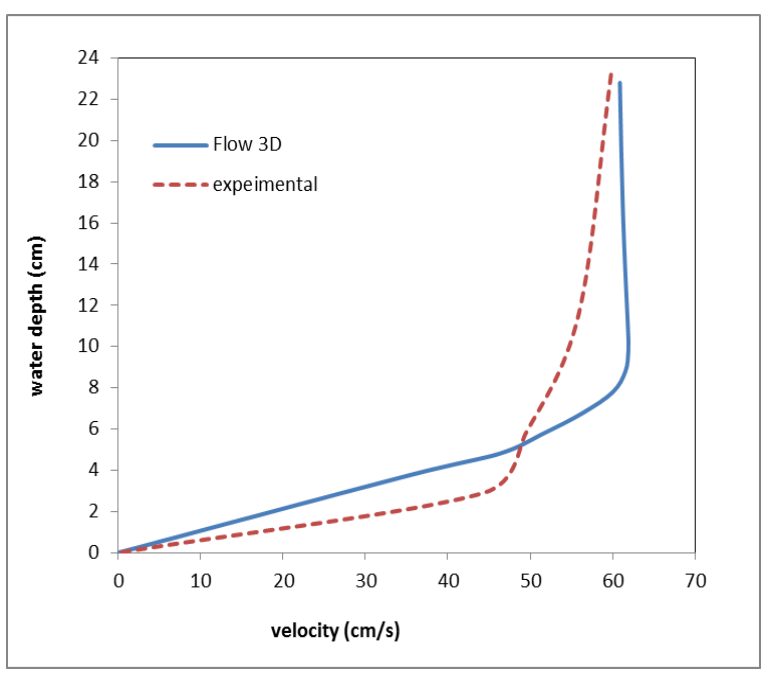

Figure 15: Comparison of velocities distribution by (Flow-3D) and experimental measurements results for test No.6. 


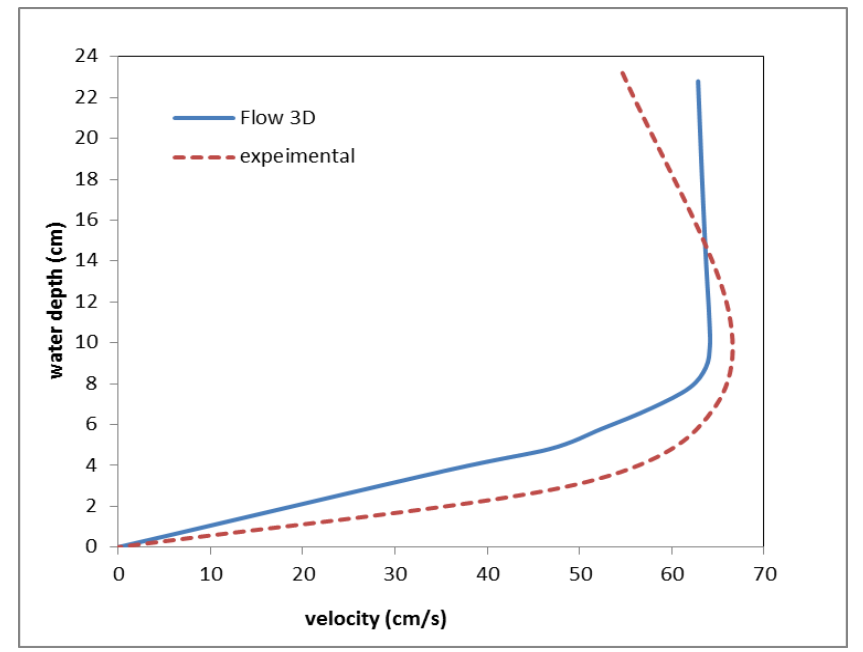

Figure 16: Comparison of velocities distribution by (Flow-3D) and experimental measurements results for test No.7.

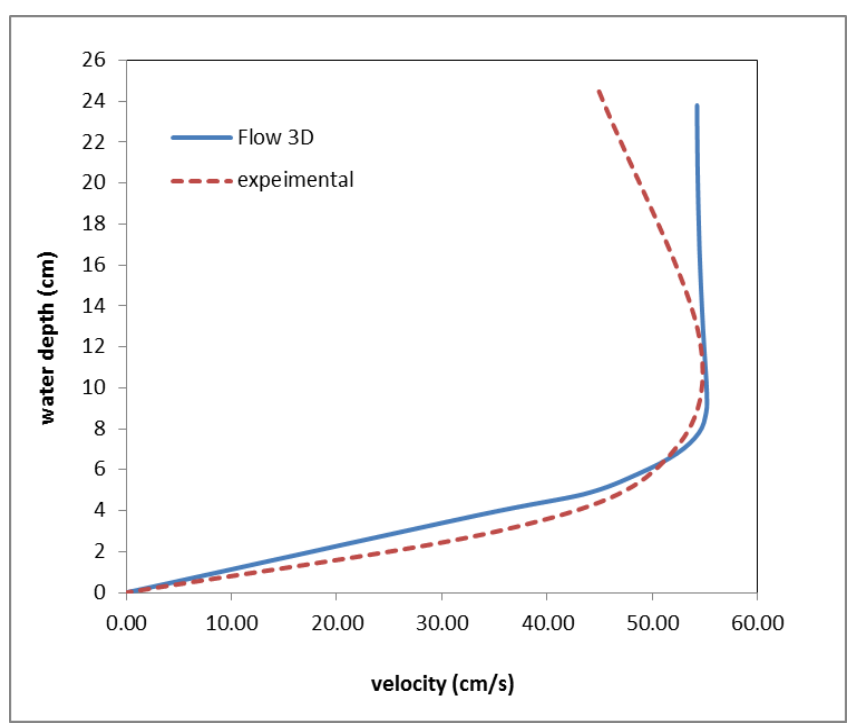

Figure 17: Comparison of velocities distribution by (Flow-3D) and experimental measurements results for test No.8.

\subsection{Results of the Bed Velocity}

In this section, the results of the validation process of the bed velocity at downstream stilling basin were presented in graphs and were discussed. The bed velocity was validated against similar laboratory tests, as shown in figure 18 and table 4.

Based on the results, figure 18 indicates that the numerical results provided satisfactory expectations from which it was concluded that the numerical model is capable of describing the bed velocity at downstream stilling basin. It could be further stated that the discrepancies of numerical results were in a range of less than $+/-25 \%$.

It was obvious that the discrepancies of numerical results and experimental data results were in a range of less than
$+/-25 \%$ for almost all of the experiments. This was attributed to the fact that few points indicated discrepancies above $+/-25 \%$.

In general, it could be stated that the numerical model was capable of reproducing most of the important features of the experimental data. It could be further more stated that the numerical results were perfectly acceptable.

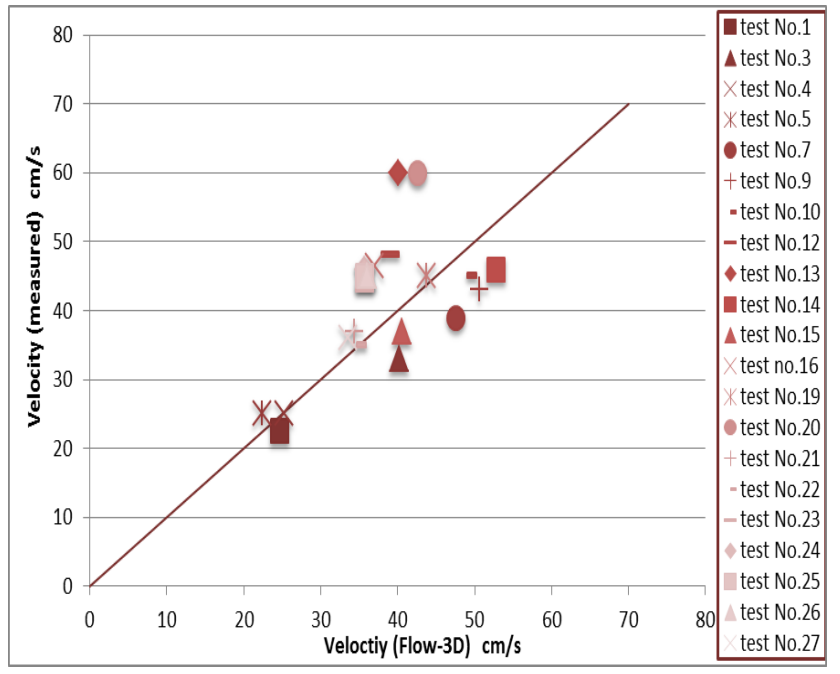

Figure 18: Validation between $\mathrm{V}_{\mathrm{b}}$ measured and $\mathrm{V}_{\mathrm{b}}$ (Flow 3D)

Table 4: Different values of velocities

\begin{tabular}{|c|c|c|c|}
\hline test & $Z$ & $\cup$ (flow-3D) & $\cup$ (measured) \\
\hline No. & $\mathrm{Cm}$ & $\mathrm{cm} / \mathrm{s}$ & $\mathrm{cm} / \mathrm{s}$ \\
\hline test 1 & 3.8 & 24.7 & 22.5 \\
\hline test 3 & 3.8 & 40.19 & 32.89 \\
\hline test 4 & 3.8 & 25.29 & 25 \\
\hline test 5 & 3.8 & 22.36 & 25 \\
\hline test 7 & 3.8 & 47.56 & 39 \\
\hline test 9 & 3.8 & 50.6 & 43 \\
\hline test 10 & 3.8 & 49.13 & 45 \\
\hline test 12 & 3.8 & 39.03 & 48 \\
\hline test 13 & 3.8 & 40.12 & 60 \\
\hline test 14 & 3.8 & 52.75 & 46 \\
\hline test 15 & 3.8 & 40.52 & 37 \\
\hline test 16 & 3.8 & 37.04 & 46.5 \\
\hline test 19 & 3.8 & 43.75 & 45 \\
\hline test 20 & 3.8 & 42.53 & 60 \\
\hline test 21 & 3.8 & 34.35 & 37 \\
\hline test 22 & 3.8 & 34.8 & 35 \\
\hline test 23 & 3.8 & 34.93 & 43 \\
\hline test 24 & 3.8 & 35.65 & 46 \\
\hline test 25 & 3.8 & 35.73 & 45 \\
\hline test 26 & 3.8 & 36.02 & 45 \\
\hline test 27 & 3.8 & 33.59 & 36 \\
\hline & & & \\
\hline & & \\
\hline
\end{tabular}




\section{CONCLUSIONS AND RECOMMENDATIONS}

Based on the model results, the main conclusions were as following:

1) Gate opening is one of the most important factors affect scour hole.

2) Moreover all gates of the barrage should be kept opened at the same height in order to uniformly distribute the discharge and obtain a relatively smaller scour hole.

3) The particles movement depends on the quantity of the passing discharge per vent.

From the numerical simulation phase, the following were deduced about (Flow-3D) model:

1) It is validated against extensive laboratory investigations.

2) It is capable of reproducing most of the important features of the experimental data and numerical results.

3) It is reproduced numerical results that are perfectly acceptable.

4) It is provided discrepancies of the numerical results are in a range of less than $+/-25 \%$.

5) It is provided numerical results that indicated a promising compatibility with the numerical results and with the experimental data.

6) It has a friendly interface.

7) It can be implemented easily.

In general, Flow-3D can be very useful for structural design of hydraulic structures. Velocity profiles can be rendered with post-processing software and can be helpful in that design phase.

\section{REFERENCES}

[2] Anderson, A.G. (1970). "Tentative design procedure of riprap lined channels", Project report No. 96, St. Antony Falls Hyd. Lab., Minneapolis, Minnesota.

[13] Dargahi, et al. (2010) "Flow characteristics of bottom outlets with moving gates". Journal of Hydraulic Research, 48(4):476-482, 2010.

[1] Ebtehal Sayed Mohamed et al.(2015)" Stability of protection layer at downstream of major hydraulic" International Journal of Emerging Technology and Advanced Engineering (ISSN 2250-2459, ISO 9001:2008 Certified Journal, Volume 5, Issue 7, July 2015).
[16]Flow-3D. (2010). User Manual Version 9.4, Flow Science.

[8]Graf, W.H. (1971)." Hydraulics of sediment transport." McGraw - Hill, New York.

[5]Isbash (1936) "stone sizing criteria" Technical Supplement 14C, 210-VI-NEH, August 2007.

[4] Knieb, H.G. (1977). "Bemmessung Von schuttsteindeckwerken im verkehrswasserbau" teil 1: Lose steinschuttungen, Mitt. B:.d.BAW, No. 42

[6]Mavis, F.T., and L.M. Laushey (1948). "A Reappraisal of the beginning of bed movement competent velocity, intern. Assoc. Hyd. Res., 2d Meeting, Stockholm

[12] Miguel Rocha Silva (2012) "3D numerical modeling of flow along spillways with free surface flow Complementary spillway of Salamonde". Instituto Superior Técnico, Civil Engineering Department.

[10]Osama Khairy Saleh (1995)" River Training And Protection For Reach Downstream Of Hydraulic Structures" Zagazig University Faculty of Engineering water and water structures Engineering Department.

[9]Römisch, K. et al.(1995)"New Assuit Barrage Hydraulic Model Investigation of Modified Layout 3-6, Barrage Model, Phase 2. July 201, HRI-159/2011"

[3]Simons, D. and Senturk, F. (1977) "Sediment transport technology", water Resources Publications, Fort Collins, Colorado. .

[11] Seyed Morteza Sadat-Helbar and Javad Farhoudi (2008)" Shear Velocity Method to Riprap Sizing at Downstream of Stilling Basins" World Applied Sciences Journal 4 (1): 116-13, 2008 ISSN 1818-4952@ IDOSI Publications, Department of Irrigation and Reclamation Engineering,Faculty of Soil and Water Engineering, University of Tehran, Iran.

[14]Seokkoo Kang, Fotis Sotiropoulos (2012) "Numerical modeling of 3D turbulent free surface flow in natural waterways" Advances in Water Resources Volume 40, May 2012, Pages 23-36

[15]Silvan Hug and Thomas Staubli(2012) "Comparison of measured path velocities with numerical simulations for heavily disturbed velocity distributions" IGHEM 2012, Trondheim

[7]United State Bureau of Reclamation (USBR) (1958), "Hydraulic design of stilling basins and Energy dissipators" water resources technical publication, Denver, Colorado. 


\section{LIST OF ABBREVIATIONS}
AB : Assiut Barrage
CFD : Computational Fluid Dynamics

C.S.No.1 : cross section number 1
a.s.L : Above sea level
D.S. : Downstream

D.S.W.L : Downstream Water Level

FS : Feasibility Study

HPP : Hydro Power Plant

HRI : Hydraulic Research Institute

MWRI : Ministry of Water Resources and Irrigation

NAB : New Assiut Barrage

SDV : Standard deviation of the velocity fluctuations.

U.S : Upstream

USBR : United States Bureau of Reclamation

U.S.W.L : Upstream Water Level.

3D : Three Dimensional Model

\section{LIST OF SYMBOLS}

C : Coefficient (0.86 for high turbulence and 1.20 for low turbulence)

$\mathrm{D}_{50}$ : Mean size of riprap particles

$\mathrm{D}_{100}$ : Maximum size of riprap particles

$\mathrm{G}$ : Acceleration of gravity

$\mathrm{L}_{\mathrm{r}} \quad$ : Length scale ratio.

Q : Discharge

$\mathrm{V}_{\mathrm{av}}$ : Is the average mean velocity

$\mathrm{V}_{\mathrm{b}}$ : The bottom velocity at $(0.9 \mathrm{Y})$ from surface of water $(\mathrm{L} / \mathrm{T})$

$\gamma_{\mathrm{s}} \quad$ : Specific weight of stone

$\gamma_{\mathrm{w}}:$ Specific weight of water

$\Delta^{\prime} \quad$ : Relative density of the submerged riprap 